\title{
A REPRESENTAÇÃO FEMININA NO RIO DE JANEIRO: A INFLUÊNCIA DO CAPITAL POLÍTICO HERDADO NO SUCESSO ELEITORAL
}

\author{
Manuela Lenkic ${ }^{1}$ \\ Philippe Guedon ${ }^{2}$
}

\section{Resumo}

O presente trabalho investiga o perfil da representação política, sobretudo feminina, à nível local nas duas casas legislativas localizadas na cidade do Rio de Janeiro: a Assembleia Legislativa (ALERJ) e Câmara dos Vereadores (CMRJ). O período de análise são as três últimas legislaturas. A metodologia empregada é a análise biográfica dos representantes para observar o peso da variável genealógica no sucesso eleitoral deste parlamentar. A hipótese do estudo é de que muito embora seja um traço característico na política brasileira a ocupação de cargos eletivos por indivíduos da mesma família, esse é um traço mais presente na representação feminina, uma vez que este grupo utiliza deste capital político "herdado" como forma de superação dos constrangimentos institucionais e socioculturais que limitam ou dificultam a sua participação. Nos resultados, observa-se que, de fato, o fenômeno é mais recorrente no gênero feminina, nas duas casas legislativas e em todo o período. Assim, leva-se a questionar sobre a superação da desigualdade de gênero ainda com o incremento do número da representação feminina, tal que na realidade local a chancela masculina, biográfica, é fundamental para a eleição.

Palavras-chave: representação feminina, genealogia, capital político, nível local.

\footnotetext{
${ }^{1}$ Graduanda em Relações Internacionais na Universidade Federal do Rio de Janeiro e em Ciências Sociais na Escola de Ciências Sociais do CPDOC/FGV. E-mail: manuela.lenkic@ @gv.br.

${ }^{2}$ Bolsista de mestrado pela CAPES/CNPQ no programa de pós-graduação em História, Política e Bens Culturais no CPDOC/FGV. Bacharel em Ciência Política pela Universidade Federal do Estado do Rio de Janeiro. E-mail: philippe.guedon@fgv.br.

CSOnline - Revista Eletrônica de Ciências Sociais, Juiz de Fora, n. 23 (2017), pp. 193-208
} 


\section{Introdução}

Em pesquisa realizada pelo IBOPE, em $2014^{3}$, $41 \%$ dos entrevistados respondeu que o incremento da participação feminina na política melhoraria a sua qualidade. Ao contrário, apenas $9 \%$ pensam que o aumento representaria desvantagens à política. No entanto, apesar de uma opinião considerável a favor de maior representação, o gênero mantém-se como diferenciador no processo eleitoral. As análises da Ciência Política atestam que o gênero, assim como outras características dos indivíduos, são importantes componentes na construção de um candidato bem sucedido eleitoralmente. .

Esses estudos são encontrados na literatura de elites políticas. Dentro da temática de análise de perfil social, é consenso que determinados perfis de candidatos são mais propensos à conquista do cargo eletivo. Para tal, a produção temática argumenta que quanto maior a articulação de capitais por parte do candidato, simbólicos ou materiais, maiores são as suas chances. (Rodrigues, 2002; Marenco, 1997). Outros afirmam que as organizações partidárias agem de maneira a maximizar suas chances eleitorais e, para tal, selecionam e apoiam estrategicamente alguns candidatos em detrimento de outros (Braga, Veiga e Miríade, 2009). De modo geral, o background dos candidatos importa no sucesso eleitoral.

Neste presente trabalho buscamos trabalhar o perfil da representação feminina nas duas maiores instâncias legislativas no estado do Rio de Janeiro: a Assembleia Legislativa do Estado do Rio de Janeiro e a Câmara Municipal do Rio de Janeiro. O período de análise compreende 2007-2010; 2011-2014; 2015-atusl (Alerj) e 2009-2012; 2013-2016; 2017-atual (CMRJ). A hipótese central do artigo é de que, a despeito da baixa representatividade proporcional feminina, parte substancial das eleitas tem como característica a investidura de um capital político de origem genealógica. Ou seja, são comuns os casos nas casas legislativas de eleitas que são parentes de outros ocupantes de cargos à nível local ou nacional. A argumentação não ignora que esse seja um traço comum na política brasileira. No entanto, argumentamos que essa característica é ainda mais central no caso das mulheres eleitas visto a realidade local e a frequência das repetições de nomes e trajetórias. A hipótese central é que o capital político herdado influi de maneira mais sistemática no sucesso eleitoral das mulheres.

\footnotetext{
${ }^{3}$ Os dados da pesquisa foram retirados de: http://www.cut.org.br/noticias/41-dos-brasileiros-acreditamque-mulheres-melhoram-a-politica-diz-ibope-9d1a/ (Acesso em 10/06/2017)

CSOnline - Revista Eletrônica de Ciências Sociais, Juiz de Fora, n. 23 (2017), pp. 193-208
} 
Metodologicamente, portanto, o presente trabalha qualifica e classifica a representação feminina a partir do seu perfil biográfico, principalmente a partir do possível apadrinhamento e transferência de capital político via genealogia. As bases acessadas para a construção do banco de dados foram extraídas tanto dos sites institucionais das casas legislativas, em perfis próprios, em sites dos eleitos, e no Dicionário Histórico Bibliográfico Brasileiro do CPDOC/FGV. O banco de dados construído contou com reconstrução de genealogia familiar na política, referência de político já consolidado (portador de capital), grau de parentesco e cargo ocupado. Em caso de políticos com diversos cargos, foi classificado a partir do cargo com maior visibilidade à nível nacional.

De modo a responder os objetivos propostos, o artigo está dividido da seguinte forma, além desta introdução: (i) discussão sobre a análise de perfil social da representação política nacional; (ii) o peso das características minoritárias na política pela literatura; (iii) a representação feminina para além do controle institucional (iv) análise dos resultados; (iv) considerações finais. De modo geral, partiremos dos constrangimentos institucionais e sociológicos para adentrar na representação à nível local e o seu perfil.

\section{Perfil social na representação política: a lógica do recrutamento}

Recentemente no campo da Ciência Política brasileira tomou forma o campo de análise dos partidos políticos a partir do recrutamento partidário. Esse termo indica que os partidos deteriam controle de toda a produção da representação nacional, desde o nível local até o federal. Segundo essa abordagem, os partidos deteriam controle sobre os processos que compõem esse processo: a filiação, formação de quadros e seleção de membros para ocupar cargos na burocracia estatal ou interna (Peres e Machado, 2017). Dentro desse processo de seleção, os partidos incentivariam indivíduos com determinadas características sociais, as quais teriam maior potencial eleitoral (Costa, Bolognesi e Codato, 2015).

É a partir dessa nova área de estudos que autores brasileiros se detiveram ao perfil da representação nacional, a fim de indagar indiretamente sobre os filtros do processo de recrutamento. De início, os estudos centraram atenção naqueles indivíduos que "chegaram lá", ou seja, aqueles que ocupariam cargos públicos eletivos. (Perissinotto e Miríade, 2009). Seria, assim, um estudo de elites. 
Dentro dessa agenda, Marenco (1997) analisou o perfil da representação política para a Câmara dos Deputados de 1986-1994; comparando-a com a representação de 19461962. A ideia central do artigo é testar se a representação da política nacional atingiria o nível de apresentar-se como constituinte de um campo político, no sentido de Bourdieu (1989). Este traria em si regras e simbologias próprias. Para assumir a ideia de que havia nesse período um campo político constituído, a representação deveria estar sendo composta majoritariamente por indivíduos com bagagem dentro das legendas partidárias e altamente profissionalizados. No entanto, ao realizar a análise de dados, identifica que a Câmara dos Deputados tem volatilidade eleitoral alta, ou seja, as taxas de renovação parlamentar são significativas. Além disso, os vínculos dos eleitos com os partidos políticos são marcados pelo pouco espaço de tempo. Não são raros os indivíduos com filiações próximas ao período da eleição. Assim, nesse ambiente, os mais representados eram indivíduos com trajetória profissional já consolidada fora do mundo da política, bem como escassos vínculos partidários. Ao fim, conclui que a representação após a Constituinte criou uma erosão intra-elite; rejeitando, portanto, a ideia de um campo político fechado na arena parlamentar.

A análise de Marenco (1997) trabalha com as legislaturas como um bloco monolítico de representação. Em passo complementar, buscando identificar se havia diferenças entre os partidos políticos, Rodrigues (2002) analisa a Câmara dos Deputados a partir do perfil social de seis partidos: PPB, PFL, PMDB, PSDB, PDT e PT. Estes partidos, junto, possuíam $84 \%$ do total de cadeiras. Segundo o autor, os perfis dos representantes variam de acordo com a legenda e ideologia. Dentre as categoriais sociais trabalhadas estão "ocupação", "patrimônio" e "instrução". Como hipótese, tem que partidos de esquerda apresentariam "portas de entrada" mais abertas à diversidade de perfis, sobretudo com ampliação da participação de setores populares. Na análise dos resultados observa que existe uma orientação ideológica; uma vez que dentre os empresários eleitos, por exemplo, 64\% deles eram de partidos de direita. Por outro lado, na esquerda do espectro político, há alta escolarização devido à representação de setores intelectualizados como professores universitários, mas garante alguma possibilidade de ascensão de indivíduos de origem popular. De modo geral, indica que os partidos políticos recrutam representantes em diferentes espaços da sociedade, a depender da estratégia e posicionamento ideológico.

Esses estudos são formas de entender o recrutamento, ao menos em parte. Bolognesi (2009), por sua vez, indica que existem outras fases do recrutamento que CSOnline - Revista Eletrônica de Ciências Sociais, Juiz de Fora, n. 23 (2017), pp. 193-208 
possam revelar as diferenças entre as legendas. A que defende, em sua dissertação, é que se analise também o processo de seleção que as elites partidárias realizam na formação da nominata do partido; o processo de seleção de candidaturas. Segundo ele, as elites partidárias agiriam de maneira estratégica a maximizar suas possibilidades eleitorais e, assim, sobrerepresentariam determinados perfis em detrimento de outros.

O mesmo autor trabalha com as listas partidárias do PT e do PFL para entender se existem diferenças entre os partidos no que tange a ocupação profissional. Observa que a ideologia interfere na produção da representação visada por esses partidos, uma vez que no PT há maior frequência de trabalhadores da educação e alguma permeabilidade de setores populares, enquanto no PFL há maior frequência de profissionais liberais. Sendo assim, vê que os partidos não são indiferenciados no que tange à seleção.

Para além do perfil ocupacional, outros autores trabalharam com mais variáveis, tais como gasto de campanha, partidos e a própria ocupação. No artigo intitulado "Dinheiro, profissão e partido nas eleições legislativas", Cervi, Costa, Codato e Perissinotto (2015) analisam que os que mais obtêm êxito eleitoral são aqueles que se intitulam políticos profissionais, seguido pelos profissionais liberais. Enquanto isso, se há abertura nas candidaturas para os trabalhadores assalariados, o sucesso eleitoral destes é diminuto, visto que apenas 3,4\% deles conquistaram os cargos. Em relação ao dinheiro gasto de campanha, vê que há maior volume de recursos para os políticos profissionais, o que corrobora tanto a ideia de ordenação informal da lista partidária de Braga (2008) quanto o maior peso das doações privadas para os incumbentes (Silva e Gonçalves, 2016).

\section{Explicações do (in)sucesso eleitoral para além das características socioprofissionais}

Recentemente, outras variáveis foram utilizadas nos estudos de recrutamento, principalmente cor/raça e gênero. Nesses estudos, a ideia central é que ter características minoritárias na política - mas majoritárias na sociedade brasileira - como ser negro e mulher afetam negativamente as chances eleitorais. No caso da representação de negros ou apenas não brancos, Campos e Machado (2015) utilizam da autoclassificação de cor e raça no TSE, bem como análise das fotos dos candidatos para verificar os vieses no recrutamento partidário, as desigualdades de recursos na campanha e também o resultado final da representação nas eleições para vereador do Rio de Janeiro e São Paulo em 2012. No que tange ao processo de recrutamento, verifica que há um filtro no lançamento das candidaturas, que fazem os não brancos serem menos representativos; no entanto, o maior filtro acontece na análise da representação, na qual os não brancos apenas atingem 16,4\% 
em São Paulo e 9,8\% no Rio de Janeiro. No perfil sociodemográfico desse grupo - não brancos - ainda identifica que possuem menores patrimônios e níveis de escolaridade mais baixos, ou seja, os não-brancos possuem menores recursos simbólicos e materiais eleitoralmente valiosos. Nas receitas dos candidatos para a campanha, observa diferença significativa no recebimento de maiores recursos para os brancos ${ }^{4}$. Como apontam, do ponto de vista sociológico:

[...] os não brancos enfrentam dificuldades maiores de ascensão à medida que se acirra a competitividade por recursos socialmente valiosos nas esferas em que eles penetram. (Campos e Machado, 2015, p.142)

No mesmo artigo, identificam que as mulheres no ano de 2012 receberam $69 \%$ menos recursos do que os homens, em média. Assim, é possível observar que a cota de lançamento de candidaturas em 1998 não modificou estruturalmente a representação feminina. As mulheres seguem com recursos diferenciados e maior dificuldade de inserção, a despeito de avanços tímidos nos números de representação.

Em relação à essa política adotada de lançamento de candidaturas visando à promoção da representação das mulheres, Bolognesi (2012) identifica que até o ano de 2006 os partidos utilizaram a cota de gênero ${ }^{5}$ de maneira pro forma, ou seja, não cumprindo o percentual requerido de $30 \%$. Por não haver punição aos partidos políticos, os partidos são menos constrangidos a lança-las. Além disso, no mesmo momento da aprovação da cota de gênero, foi aprovado também o aumento de número de candidatos que os partidos políticos pode lançar. Assim, as mulheres podem (e muitas vezes são) lançadas apenas para cumprir a cota ou lançadas de maneira que o partido não assegure estrutura competitiva para tal.

Também em referência as cotas de gênero, Araújo e Alves (2007) investigam o peso de variáveis estruturais, como IDH e porte da cidade, com variáveis de cunho pessoal, como gênero, idade e ocupação na explicação para a eleição. De início observam que as mulheres têm possibilidades menores de eleição do que os homens - a partir de dados para deputado federal em 2002. Além disso, identificam que as trajetórias e inserções na política são diferenciadas entre homens e mulheres. No gênero feminino há maior chance eleitoral para aquelas com mais de 35 anos e solteiras, o que evidencia um

\footnotetext{
${ }^{4}$ A variável de recurso de campanha foi controlada pela pertença a classe alta dos dois grupos, uma vez que a amostra é desigual em termos de gasto de campanha.

${ }^{5}$ A cota de gênero foi obrigatória e com punição para o não cumprimento a partir das eleições de 2010

(Alves, Pinto e Jordão, 2012).

CSOnline - Revista Eletrônica de Ciências Sociais, Juiz de Fora, n. 23 (2017), pp. 193-208
} 
maior tempo de construção de trajetória e acúmulo de capital político, bem como maior disposição de tempo para aquelas que não se encontram em matrimônio.

Trabalhando gênero, raça e ocupação, Bolognesi, Perissinotto e Codato (2016) analisam nos níveis de disposição para a atividade política. Resgatando os pressupostos de que alguns perfis são mais afeitos à política do que outros (Norris e Lovenduski, 1993; Dogan, 1999) buscam identificar os efeitos dessas variáveis no sucesso eleitoral. Classificam, assim, a variável ocupacional em níveis de disposição para a política e observa que há uma forte relação entre ser do sexo feminino e ter alguma ocupação de baixa disposição. Corrobora para isto o fato de que a categoria ocupacional mais mencionada entre as mulheres é a de dona de casa com $6,4 \%$.

Da mesma forma observam desvantagens em relação aos que se declaram negros, uma vez que também há maior concentração de negros nas atividades com menor disposição para política. Sobre as mulheres, a ocupação prediz alguma chance de vitória eleitoral - aquelas com maior disposição para a política, como advogadas e empresárias; resultado não encontrado para os negros, em que a variável ocupação não interfere no seu destino eleitoral. Em síntese, argumentam que candidatas competitivas são mais competitivas quando possuem atividades profissionais com alta disposição para política, enquanto os negros, mesmo os possuidores desse capital, tiveram suas chances eleitorais afetadas pela cor de pele.

São recentes os estudos na área e não se esgotam nestes. No entanto, pretendemos com essa discussão reforçar que a literatura abriu nova agenda de pesquisa ao começar a investigar o sucesso ou insucesso a partir das características sociais. Porém, para além dos aspectos da arena eleitoral, existem barreiras anteriores à representação feminina, de ordem social, que serão explicitados na seção seguinte.

\section{Os entraves à participação feminina além da esfera eleitoral}

Na seção anterior foram trabalhados - alguns indiretamente - os percursos que as mulheres (assim como outros grupos sociais) devem percorrer para atingir ao posto de eleito, tais como a adesão a um partido político, a seleção de candidatos, a estrutura de competição e, por fim, a eleição. No entanto, a fim de entender a representação feminina de maneira mais abrangente, é preciso que se atente a fatores socioculturais que explicam a pouca adesão das mulheres à carreira política e, por conseguinte, sua menor vitória dentre os pleitos eleitorais. 
Essas particularidades variam, assim, a partir de fatores históricos e estruturais que contribuem para entendermos a conjuntura. Logo, a (baixa) participação feminina na política tem como variáveis explicativas as estruturas gerais de opressão, dadas pela estrutura social e sua formação, como também das próprias barreiras institucionais. (Biroli e Mota, 2014)

A formação histórica brasileira é marcada pela "tradicionalidade" nas relações de gênero. Esse conceito carrega no seio de seu significado uma divisão binária e estereotipada de gênero; que quando relativa à família e à vida social, o homem seria então o patriarca, chefe de família, enquanto a mulher lhe caberia uma posição subalterna a ele. Nesse sentido então, há uma divisão de tarefas e principalmente de domínios de atuação, onde a vida pública seria mais afeita ao masculino enquanto a vida privada e doméstica ao feminino. É no cerne dessa binaridade que se estabelece o que entendemos por 'divisão sexual do trabalho' (Araújo, 2006).

Essa é uma das explicações para compreender o atual cenário de baixa representação feminina no âmibto político-institucional. É sob a égide dessa divisão que se perduraram leis que barravam legalmente a participação e os direitos políticos das mulheres, já que ele era resguardado ao voto do patriarca -pai ou marido. As lutas feministas pelo sufrágio universal feminino, por exemplo, conseguem mudar essa realidade institucional, porém, não representou acesso igualitário ao campo político (Miguel, 2014). Outrossim, essa divisão sexual do trabalho opera ao mesmo tempo no campo simbólico, mesmo com o impedimento legal aniquilado, à medida que impõe constrangimentos sistemáticos as possibilidades da mulher (Biroli e Mota, 2014). Isso acontece desde muito cedo, na socialização feminina, onde as preferências já são prédefinidas e então inibem e estimulam certas condutas, preferências, etc.

Configura-se, assim, uma das razões da suposta 'não-aptidão' feminina para a carreira política. A possibilidade ou estímulo que se daria às mulheres para perseguirem esse tipo de objetivo não é real e efetivo em sua socialização. Mesmo com a inserção da mulher no mercado de trabalho, a conquista de uma maior independência da figura tradicional da "dona de casa", existem limitações estruturantes da vida das mulheres que tem um grande impacto sobre o tempo dedicado à política, como por exemplo a dupla jornada de trabalho a que são incumbidas (Araújo, 2009). Pode-se ver, portanto, que os percalços de uma mulher que se aventura na arena política vão além da conduta individual 
de um dirigente partidário ou da escolha do eleitor; possui explicações do campo simbólico cultural que aqui se ergueram.

De modo a investigar aquelas que superaram as barreiras tanto institucionais quanto socioculturais, segue, portanto, a análise biográfica e a construção do perfil da mulher eleita à nível local no Rio de Janeiro.

\section{Análise de dados: a representação política feminina e o peso do capital político herdado}

Quando pensamos a representação feminina, o primeiro dado que interpela a análise é que a representação das mulheres à nível local é mais frequente do que em âmbito nacional. Se no nível nacional as porcentagens não passaram de $10 \%$ nas três últimas composições das legislaturas (2006 - 9\%; 2010 - 9\%; $2014-10 \%$ ), a pior representação à nível local foi na Assembleia Legislatura do Rio de Janeiro em 2014, com $11 \%$. É notório que os custos de vitória a esses cargos são menores, sejam eles financeiros ou de recursos de capitais sociais e simbólicos, mas é representativo que as taxas sejam maiores nesses ambientes. Na tabela abaixo é possível observar tais representações:

Tabela 1 - Representação feminina (\%)

\begin{tabular}{|l|c|c|c|c|c|c|}
\hline & 2006 & 2008 & 2010 & 2012 & 2014 & 2016 \\
\hline Vereadoras & - & 25 & - & 16 & - & 14 \\
\hline Deputadas Estaduais & 13 & - & 19 & - & 11 & - \\
\hline
\end{tabular}

Fonte: Tribunal Superior Eleitoral. Dados sistematizados pelos autores

À primeira vista, a representação feminina em maiores níveis poderia indicar o empoderamento desse segmento populacional como também maior capacidade de combate às desigualdades históricas da representação brasileira. Mesmo que as bandeiras das eleitas não representassem, por vezes, indicativos de alusão específica as causas históricas de luta do movimento feminista, a presença delas no ambiente valeria por si, no sentido de ocupar um lugar que, de fato, também as pertence.

O que o presente artigo problematiza, no entanto, é que as eleições dessas mulheres ainda carregam consigo marcas da não-autonomia de suas candidaturas. $\mathrm{Ou}$ seja, para que sejam eleitas, utilizam de capitais políticos a partir da sua genealogia para afirmar-se como candidata viável eleitoralmente. Por certo, a manutenção das elites políticas no Brasil via genealogia é uma característica da política nacional - padrão também encontrado à nível local (gráfico 1). No entanto, o que os dados apontam é que esse recurso é mais frequente para as mulheres, como aponta o gráfico abaixo (gráfico 2). 
Isso reflete estratégias de articulação de capitais, uma vez que as mulheres apresentam tendências, segundo a literatura, de serem mais desprovidas se comparadas aos homens.

Gráfico 1 - Percentual de capital político herdado por cargo/ Gráfico 2 - Presença genealógica por gênero

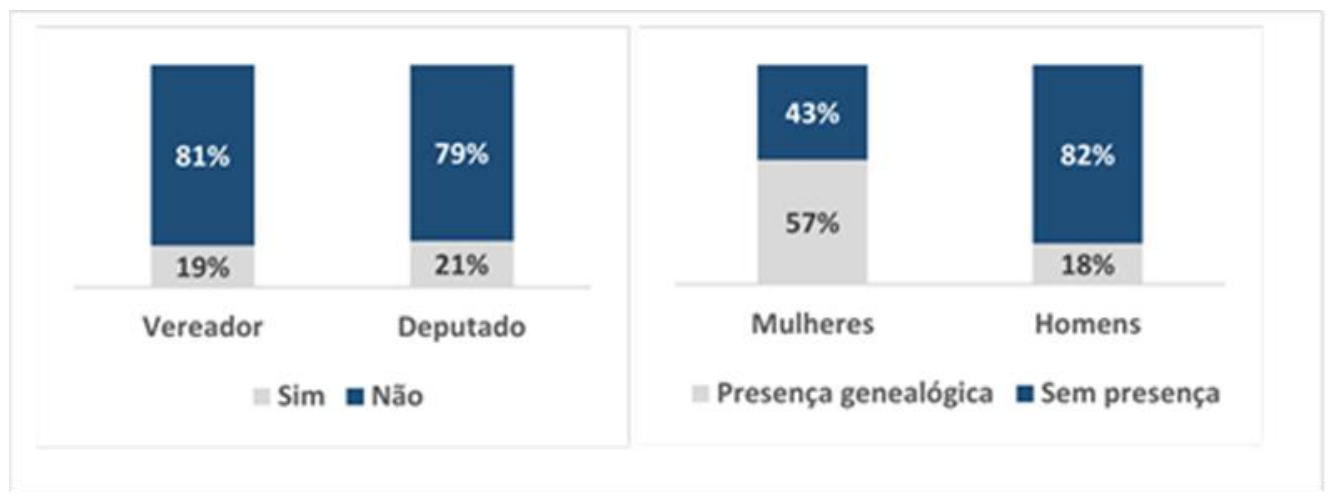

Fonte: Sites oficiais da CMRJ, ALERJ e Tribunal Superior Eleitoral. Dados sistematizados pelos autores.

Os padrões são semelhantes nas duas casas legislativas. A maior parte das mulheres eleitas contam com o que chamamos neste artigo de capital político herdado, enquanto a presença nos homens é menor. Mais da metade das mulheres eleitas contam com pais, maridos e tios no mundo da política.

Gráfico 3 - Presença genealógica (capital político) por gênero e casa legislativa

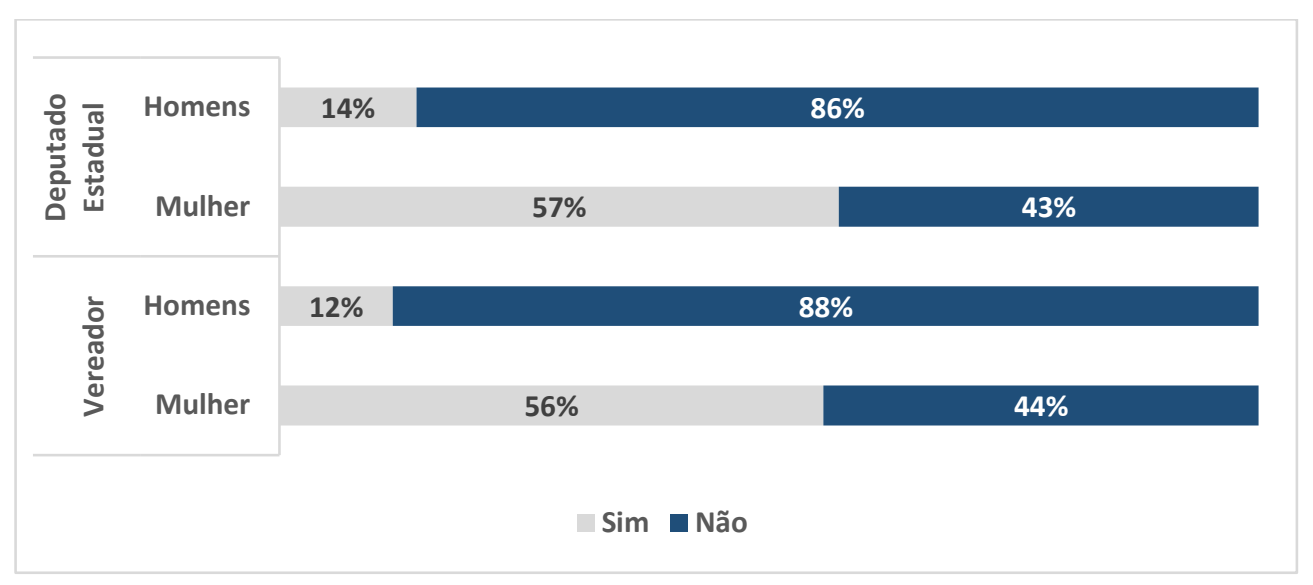

Fonte: Sites oficiais da CMRJ, ALERJ e Tribunal Superior Eleitoral. Dados sistematizados pelos autores.

De modo que analisamos as três últimas legislaturas, é possível observar que este não é um fenômeno circunscrito a um ciclo eleitoral. Comparando a composição das legislaturas, em ambas as casas, as tendências são semelhantes. Na Câmara Municipal do Rio de Janeiro na legislatura de 2013-2016 há o maior percentual; enquanto na Alerj o período é de 2011-2014. 
Gráfico 4 - Presença genealógica por legislatura na Câmara dos Vereadores por gênero

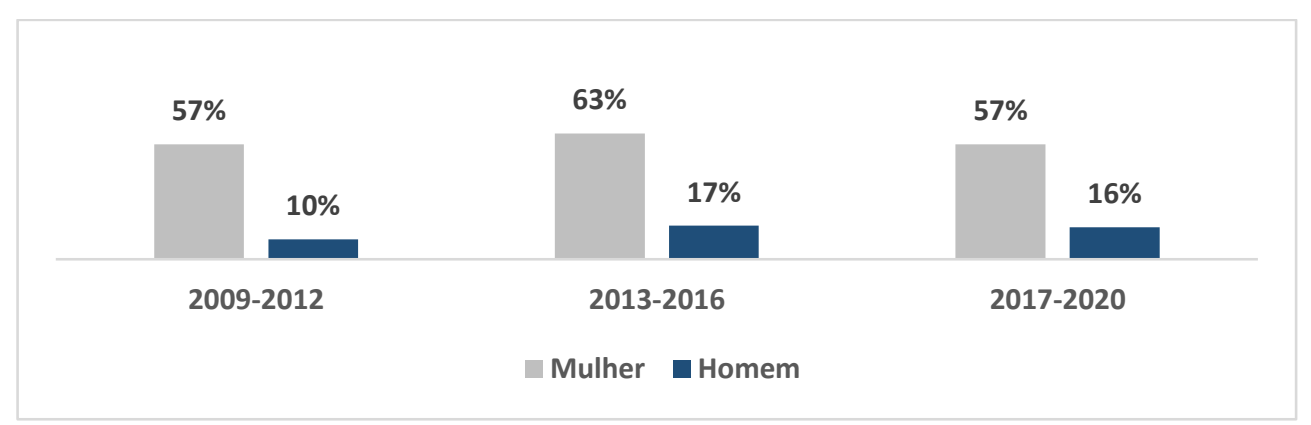

Fonte: Sites oficiais da CMRJ, ALERJ e Tribunal Superior Eleitoral. Dados sistematizados pelos autores.

Gráfico 5 - Presença genealógica por legislatura na ALERJ por gênero

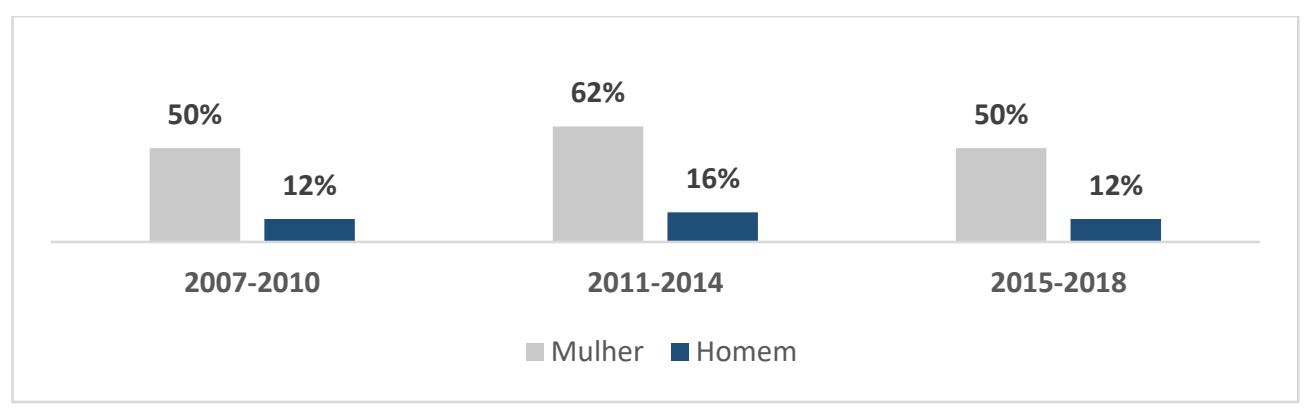

Fonte: Sites oficiais da CMRJ, ALERJ e Tribunal Superior Eleitoral. Dados sistematizados pelos autores.

De maneira geral, os vínculos entre os eleitos e os parentes que lhe conferem capital político são diferentes a depender do gênero do eleito. Em linhas gerais, há maior tendência de "empréstimo" de capital político de parentes homens para os eleitos. Isso fica mais claro no gráfico abaixo:

Gráfico 6 - Origem do capital político herdado na ALERJ

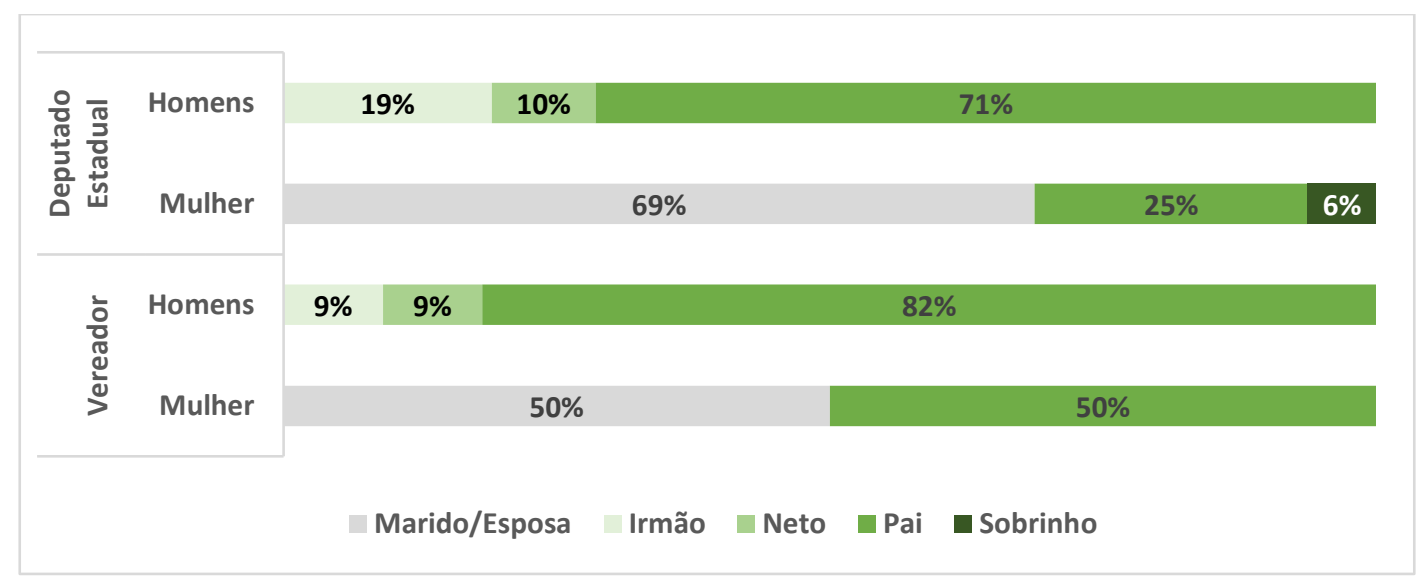

Fonte: Sites oficiais da CMRJ, ALERJ e Tribunal Superior Eleitoral. Dados sistematizados pelos autores. 
No gráfico acima é possível ver que nas mulheres a origem mais comum do capital político é do marido. Significativo também é o fato de que o contrário, ou seja, de uma esposa transferir capital político para o marido, não seja representado nessas legislaturas, em ambas as casas. No caso dos homens eleitos, a maior presença de origem é do capital político paterno, atingindo $71 \%$ na ALERJ. O que esse ponto demonstra, além da maior presença do uso desse tipo de capital no gênero feminino, é o sentido de origem, que diz respeito usualmente a partir do matrimônio.

Por fim, ainda na linha de origem do capital político herdado, a maior parte do capital político herdado na ALERJ advém de prefeitos de cidades do interior e região metropolitana do Rio de Janeiro (gráfico 7). São exemplos disso, Renata do Posto (origem do capital: Nelson do Posto - Ex-Prefeito de Guapimirim), Jane Cozzolino (origem do capital: Renato Cozzolino - Ex-Prefeito de Magé) e Claíse Maria Zito (origem do capital: Jose Camilo Zito dos Santos Filho - Ex-Prefeito de Duque de Caxias). Nesse caso, a estratégia é de utilizar a circunscrição municipal como impulsionadora do sucesso eleitoral desses candidatos dentro da estrutura genealógica.

Já na Câmara dos Vereadores, a origem majoritária é de deputados estaduais. Interessante notar que o capital político herdado é, de maneira geral, oriundo de políticos de outras esferas de representação, com pouca transferência de ex-vereadores para os atuais. Há um padrão de aquisição desse capital político herdado em cargos de maior abrangência de representação na Câmara dos Vereadores.

Gráfico 7 - Cargo do autor da herança do capital político

\begin{tabular}{|c|c|c|c|c|c|c|}
\hline \multirow{2}{*}{$\begin{array}{l}\text { Deputado Estadual } \\
\text { Vereador }\end{array}$} & $12 \%$ & $24 \%$ & $3 \%$ & $44 \%$ & & $15 \%$ \\
\hline & \multicolumn{3}{|c|}{$50 \%$} & $20 \%$ & $10 \% \quad 5 \%$ & $15 \%$ \\
\hline \multicolumn{2}{|c|}{$\begin{array}{l}\text { Deputado Estadual } \\
\text { Senador }\end{array}$} & $\begin{array}{l}\text { Deputado Federa } \\
\text { Vereador }\end{array}$ & & $\begin{array}{l}\text { Governador } \\
\text { Vice-Prefeito }\end{array}$ & Prefeito & \\
\hline
\end{tabular}

Fonte: Sites oficiais da CMRJ, ALERJ e Tribunal Superior Eleitoral. Dados sistematizados pelos autores.

\section{Considerações finais}

As análises sobre a representação feminina partem tanto de incentivos das arenas institucionais quanto de explicações de cunho culturais e sociológicos. O questionamento dessas pesquisas é a baixa representatividade do gênero na política institucional e, assim, 
verificam-se os estrangulamentos institucionais e societais desse problema. Por isso, trabalhamos com a abordagem combinada a partir da literatura de recrutamento e seleção de candidatos - arena institucional; quando a abordagens mais sociológico-cultural.

Dentre os resultados encontrados, comprova-se a hipótese testada de que as representantes a nível local são lançadas e construídas como candidatas a partir de um acúmulo de capital político que não lhe era próprio, de origem. São comuns os casos em que parentes já consolidados no mundo da política buscam estabelecer novas gerações ou nomes em novos cargos. O uso genealógico como transferidor de capital político é recorrente nos dois gêneros, mas mais presente no gênero feminino.

Além disso, na análise das deputadas estaduais é possível ver alguma tendência de apadrinhamento a partir dos maridos já prefeitos de cidades no interior do estado para suas esposas na candidatura a deputada estadual. Estratégia esta que se mostra bem sucedida, visto que $44 \%$ das representantes no período tem esse perfil. Já nas vereadoras divide-se entre o capital herdado pelos pais e no marido. Interessante notar que não há relação de sentido inversa; ou seja, de representantes do sexo feminino que "emprestam" capital político para os seus maridos.

Por fim, nota-se que a composição majoritária do capital político herdado na Câmara não advém de ocupantes de cargos nessa esfera. O mesmo se repete na ALERJ. Via de regra, cargos com maiores visibilidades são os autores da herança.

Em síntese, é mais um trabalho que dialoga com a questão normativa da importância da representação feminina dentro das esferas político-institucionais. Caminha, ainda, no sentido de qualificar o estudo da representação, desta vez a partir da genealogia. Como agenda futura, cabe destacar os efeitos dessa representação feminina, se o incremento gerou aumento do debate e produção de políticas públicas voltadas ao público feminino e mesmo os efeitos simbólicos de tal representação. Tal questão também pode ser observada a partir do prisma dos estudos feministas e de minorias. Os sentidos de empoderamento e autonomia podem ser empregados para questionar a representação a partir da utilização desse recurso de capital oriundo do gênero masculino.

À luz da lente que for observado, o fenômeno carece de estudos sistemáticos, para além deste presente estudo de caso, a fim de ilustrar a realidade representativa das mulheres em um todo.

\section{Bibliografia:}


ALVES; José Eustáquio; PINTA, Regina Céli; JORDÃO, Fátima. Mulheres nas eleições 2010. São Paulo: ABCP/SPPM, 2012

ARAUJO, Clara. Rotas de ingresso, trajetórias e acesso das mulheres ao legislativo: um estudo comparado entre Brasil e Argentina. Rev. Estud. Fem., Florianópolis, v.18, n.2, p.567-584, 2010.

ARAUJO, Clara; ALVES, José Eustáquio Diniz. Impactos de indicadores sociais e do sistema eleitoral sobre as chances das mulheres nas eleições e suas interações com as cotas. Dados，Rio de Janeiro ， v. 50, n. 3, p. 535-577， 2007

BIROLI, Flavia; MIGUEL, Luis Felipe. Feminismo e política: uma introdução. 1 ed - São Paulo: Boitempo, 2014. Recurso digital

BOLOGNESI, Bruno. A cota eleitoral de gênero. v.1. Paraná Eleitoral. Paraná, 2012.

BOLOGNESI, Bruno. Candidatos e eleitos: o recrutamento político nos partidos paranaenses nas eleições de 2006. Dissertação de Mestrado. UFPR, 2009.

BOLOGNESI, Bruno; PERISSINOTTO, Renato ; CODATO, Adriano . Reclutamiento político en Brasil Mujeres, negros y partidos en las elecciones federales de 2014. Revista Mexicana de Ciencias Políticas y Sociales, v. 61, p. 247-278, 2016.

BOURDIEU, Pierre. O poder simbólico. Lisboa, Bertrand, 1989.

BRAGA, Maria do Socorro Sousa. Organizações partidárias e seleção de candidatos. OPINIÃO PÚBLICA, Campinas, vol. 14, nº 2, Novembro, 2008, p.454-485

BRAGA, Maria do Socorro Sousa; VEIGA, Luciana Fernandes; MIRIADE, Angel. Recrutamento e perfil dos candidatos e dos eleitos à Câmara dos Deputados nas eleições de 2006. Rev. bras. Ci. Soc., São Paulo, v. 24, n. 70, p. 123-142, 2009

CAMPOS, Luiz Augusto e MACHADO, Carlos. A cor dos eleitos: determinantes da sub-representação política dos não brancos no Brasil. Revista Brasileira de Ciência Política, nº 16. Brasília, 2015, pp. 121-151.

CERVI, Emerson. Doações de campanha e desempenho eleitoral: Uma análise comparativa sobre as eleições para prefeitos de capitais brasileiras em 2008 e 2012. Revista de Discentes de Ciência Política da UFSCAR. Vol. 1 - n. 1 - 2013. 
CERVI, Emerson. Voto, dinheiro e diferenças regionais nas eleições brasileiras: recursos financeiros e políticos para candidatos a deputado federal em 2010. Trabalho apresentado no $8^{\circ}$ Encontro da Associação Brasileira de Ciência Política, 2012.

CERVI, Emerson; COSTA, Luiz Domingo; CODATO, Adriano e PERISSINOTTO, Renato. Dinheiro, profissão e partido: a vitória na eleição para deputado federal no Brasil em 2010. Revista Sociedade e Estado, vol. 30, Número 1, 2015 .

CHAMALLAS, Martha. Introduction to Feminist Legal Theory. Aspen Law \& Business, New York, 1999.

COSTA, Luiz Domingos; BOLOGNESI, Bruno; CODATO, Adriano. Onde estão os trabalhadores nas listas de candidatos dos partidos brasileiros?. newsletter. observatório de elites políticas e sociais do brasil. v. 2, n.2. 2015.

DOGAN, M. Les professions propices à la carrière politique. Osmoses, filières et viviers. In: OFFERLÉ, M. (ed.). La profession politique: XIXe-XXe siècles. Paris: Belin, p. 171-199, 1999

LOVENDUSKI, Joni and PIPPA, Norris. (ed). Gender and Party Politics. London: Sage, 1993.

MOTA, Fernanda Ferreira and BIROLI, Flávia. O gênero na política: a construção do "feminino" nas eleições presidenciais de 2010. Cad. Pagu [online]. 2014, n.43, pp.197-231.

PERES, Paulo e MACHADO, Amanda. Uma tipologia do recrutamento partidário. OPINIÃO PÚBLICA, Campinas, vol. 23, nº 1, jan. - abr., 2017.

PERISSINOTTO, Renato; MIRÍADE, Angel. Caminhos para o Parlamento: Candidatos e Eleitos nas Eleições para Deputado Federal em 2006. Revista DADOS, v. 52, n. 2, p. 301-303, 2009.

RODRIGUES, Leôncio Martins. Partidos, Ideologia e Composição Social: Um Estudo das Bancadas Partidárias da Câmara dos Deputados. São Paulo, Edusp, 2002.

SACCHET, Teresa e SPECK, Bruno. Financiamento eleitoral, representação política e gênero: uma análise das eleições de 2006. Opinião Pública, Campinas, vol. 18, nº1, Junho, 2012, p.177-197.

CSOnline - Revista Eletrônica de Ciências Sociais, Juiz de Fora, n. 23 (2017), pp. 193-208 
SANTOS, Marenco dos. Nas fronteiras do campo político: raposas e ousiders no Congresso Nacional. Revista Brasileira de Ciências Sociais, São Paulo, v. 33, p. 87$101,1997$.

SILVA, Bruno Fernando da; GONÇALVES, Ricardo Dantas. É financiado porque é competitivo ou é competitivo porque é financiado? Intenção de voto e receitas eleitorais de candidatos ao senado em 2014. Paper apresentado no 40 encontro da ANPOCS, 2016. 